\title{
On Hourglass Model of Poetry Teaching in College English Class in China
}

\author{
Zeyuan $\mathrm{Hu}$ \\ College of Foreign Languages, Zhejiang Gongshang University, 310035, China \\ Email: sailorhu@126.com
}

\begin{abstract}
Inspired by the Input and Affective Hypothesis by Krashen, Interaction hypothesis by Long and Comprehensible Output hypothesis by Swain and absorbing the quintessence of Littlewood's teaching sequences principle and Adair-Hauck \& Cumo-Johanssen's "top-down" language instruction principle, the paper relates to the reality of college English teaching in China and presents a model of poetry teaching in CE classes. This model combines organically input and output, including receptive and productive phases, namely, activate, study practice, study focus, study focus, study practice, activate. During the whole process of teaching, the focus is gradually shifting from meaning to form, and then form to meaning. Interaction happens between the teacher and students, students and students. Activities include listening, speaking, reading, writing, translating and discussing are scientifically and systematically arranged and thus make the input and output well-connected and mutually promoting. The learning style may develop from teacher-guided learning to students' autonomous learning.
\end{abstract}

Index Terms - college English teaching, poetry in English, teaching model, hourglass

\section{INTRODUCTION}

Literature is an art of language. Poetry is the most artistic genre of literature. To learn a foreign language well, one must learn literature in the language. Nothing other than poetry in a foreign language can offer a better way of expression or better about culture and thought. "Best thought best expressed". However, the teaching of poetry has not been paid much attention or practiced very well in College English class in many universities and colleges. The reasons may be various. However the poor teaching effects in most classes may shoulder the blame. The paper attempts to make a discussion about the hourglass pattern of the teaching of English Poetry in College English class in light of some second-language acquisition theories, especially Krashen's input hypothesis and Long's interaction theory.

\section{Theoretical Background of Teaching of English Poetry in Foreign Language Class}

Stephen Krashen and Tracy Terrel developed the Natural Approach (1983) based on Krashen's input hypothesis, which holds that language acquisition occurs in a classroom with abundant comprehensible input. This means if students can understand the poetry, then acquisition will happen. Now let's look at Krashen's Hypothesis:

1) The input hypothesis: Acquisition occurs only when learners receive optimal comprehensible input that is interesting, a little beyond their current level of competence (i+1), and not grammatically sequenced, but understandable through their background knowledge, their use of context, and other extra-linguistic cues such as gestures and intonation;

2)The affective filter hypothesis: Language learning must take place in an environment where learners are "off the defensive" and the affective filter (anxiety) is low in order for the input to be noticed and gain access to the learners' thinking (Krashen, 1982)

Here, I stress two of Krashen's hypotheses because being interesting and having low affective filter (anxiety) are the most charming features of poetry learning.

The themes of English poetry include love, friendship, nature, life, etc, which are interesting to college students. The beautiful way of saying things is extremely charming to foreign language learners. For example, "Beauty is truth, truth beauty" in Keats's Ode on a Grecian Urn and "If winter comes, can spring be far behind" in Shelley's Ode to the West Wind have impressed generations of college students in China.

Students can be totally "off the defensive" when they are appreciating a poem since poems offer various possibilities of meanings to different readers and they don't need to worry about keeping up with the usual "standard" answer to questions in class. Poetry discussion between teacher and students in class provide a superb opportunity for learners to develop linguistic, imagery and cultural thinking in a relatively low anxiety.

Additionally, Long's interaction theory may also be instructive for us to improve the teaching of poetry in English class. According to Long (1983), input can be made "comprehensible" in three ways:

1) by simplifying the input, i.e., using familiar structures and vocabulary;

2) by using linguistic and extra-linguistic features, i.e., familiar structures, background knowledge, gestures; and 
3) by modifying the interactional structure of the conversation.

The first and second ways tells us how to make poetry teaching more effective in College English class. We should simplify the poem by introducing some literary methods and background knowledge, paraphrasing words and syntax in poems, using some gestures and playing some audio materials, etc.

The third way is the basis of Long's (1981) Interaction Hypothesis, which takes into account both input and learner production in promoting acquisition. Long (1983) maintains that speakers make changes in their language as they interact or "negotiate meaning" with each other. Negotiation of meaning has been characterized as "exchanges between learners and their interlocutors' as they attempt to resolve communication breakdown and to work toward mutual comprehension" (Pica, Holliday, Lewis, \& Morgenthaler, 1989). Speakers negotiate meaning to avoid conversational trouble or to revise language when trouble occurs. Through negotiation of meaning, interactions are changed and redirected, leading to greater comprehensibility. In the classroom negotiation of meaning means that both parties in a teacher-student and student-student interaction must seek clarification, check comprehension, and request confirmation that they have understood or are being understood by the other. This process is often difficult to achieve in the classroom, given the traditional roles between teachers and students. Since students are often hesitant to question or counter-question the teacher, negotiation of meaning may not occur often. Although teachers often work to provide comprehensible input through a variety of techniques, this process does not occur, both interlocutors must have equal rights in asking for clarification and adjusting what they say. Thus Long's theory implies that learners can't simply listen to input, but that they must be active conversational participants who interact and negotiate the type of input they receive in order to acquire language.

In poetry class, there is no authority. Teachers are on the equal position with their students. New criticism believes that poetry is a self-sufficient object, to understand which no need should be done to learn anything beyond the text. Students and teachers are equal in front of a poem. Every possible understanding will be welcome.

\section{BenEFITS OF TEACHING ENGLISH POETRY IN COLLEGE ENGLISH}

Obviously teaching English poetry in College English class may bring various profits from many perspectives.

Firstly, from the perspective of language acquisition, it can improve language learners' depth of perception in the language, width and depth of vocabulary acquisition. Poetry is about the most delicate part of a nation's feeling. The usage of words is through careful and thorough weighing of poets. Many Chinese students find it difficult to express deep thought and feeling in English though they have a large vocabulary since the depth of acquisition is not enough. On the phonetic, lexical, syntactical and discourse layers, poetry demonstrate the richest possibilities for a language. Take the famous poem When you are old by W. B. Yeats as an example. First the teacher should analyze the meter of rhyme scheme. There is an iambic pentameter for each line and the rhyme scheme is $a b b a$. Students will sense the beauty of English as a language.

Secondly, poetry is a cultural composite. When a student is learning a language, he or she is also learning a culture. Culture behind a language is sometimes very complex and may pose a hindrance for students to communicate successfully with people speaking the language in the culture. When teachers are explaining a poem, it is quite helpful, though not necessarily according to New Criticism, to explain the background of the poet and the poem. For example, the Christian culture and the Greek culture often have a strong influence on English poetry. T. S. Eliot's poem Waste Land is a typical example to show the heavy load of cultural heritage in one single poem. By learning these poems, students are not only learning English as a foreign language but getting contact with a foreign culture. This may improve their international insight and cultural qualities. It can improve students' interest as well.

\section{Principles of Teaching English PoEtry in COLlEge English Class}

1) Equality: put students and the language on the same footing;

2) Diversity: various different versions of interpretations of the poems should be welcome from the students to stimulate their thinking in English and create a democratic atmosphere for them to practice their oral and written English.

3) Creativity; students should be encouraged to create on the basis of poetry-appreciation (reading, analyzing and listening), they may do imitative writing. For example, the following poem is written by one of my students after the discussion of the poem Lake Isle of Innisfree by Yeats.

I will arise and go now, go to a great library,

Rows of books will I have there, of great minds read;

I will read nothing but truth and beauty,

And write down lines as mighty as those by Bede.

I will have some peace there for peace comes slow,

Madding crowd far away, nothing but beauty stays;

Body may decay while eyes full of wisdom glow,

Everyone there speaks and thinks with grace. 
I will arise and go now, for always night and day,

I have smelled the fragrance of printed sheets;

Whenever on the railway or in the busy subway,

I hear the self whisper there the soul it meets.

4) Autonomy: Poetry can open a door leading to the wonderland of English language, thought, history and culture. In recent years, students' autonomous learning is emphasized in China. But there are still problems. One reason is that students feel lost and puzzled in front of some much information and lose a sense of efficiency in English language learning. Poems are written by the greatest masters of the English language. To get the best in the shortest time, they are recommended to learn poems in English. Through the discussion in class, students will acquire the method and enjoy the happiness of reading poems in English. They may develop gradually autonomy in learning. And this is the ultimate aim of foreign language instruction.

\section{Sequences of Activities In SeCOnd Language Class}

Now the question is: how to teach poems in college English class.

Littlewood (1980) suggested that classroom practice activities be sequenced so that meaning increasingly receives more focus. In his model, activities progress through the following stages: 1) primary focus on form; 2) focus on form, plus meaning; 3) focus on meaning, plus form; and 4) primary focus on meaning (cf. Hadley, 1993).

A top-down or whole-language approach to language instruction resists reducing language to word lists, verb conjugations, discrete grammar points, or isolated linguistic elements (Adair-Hauck \& Cumo-Johanssen, 1997). In a whole-language approach, learners are presented with a "whole" text (e.g., a story, poem, song, tape-recorded listening selection), are guided through comprehending its main ideas, explore these ideas through interaction with others, and then focus on specific details and/or linguistic structures (e.g., vocabulary, grammar).By means of activities such as negotiation of meaning and joint problem solving with the teacher and classmates, learners demonstrate performance before competence; that is, they participate in a more complex task than they are capable of completing without assistance (Rogoff, 1990).

By absorbing the advantages of the above theories and relating to the reality of college English teaching in China, I hereby suggest the following Sequences of activities of English poetry in College English class:

1) Listen to the poems read by the poet or experts (appreciation of the phonetic features)

The teacher first plays a tape or downloaded audio of the poem reading. I once played the audio of Lake Isle of Innisfree read by W B. Yeats himself on BBC in 1936. The beauty and sincerity of the poet's voice arrest students' high concentration immediately. This step is called "to activate" which is extremely important to arouse students' interest. It also challenges students listening capability. They can gain some global sense about the meaning and beautiful form (rhyme, meter, rhythm). Interest and curiosity are knocking the door! Then you are expected to go to next step for they want more and clearer understanding.

2) Reading by themselves

During reading, students gain an experience of its formal meaning and beauty. This will help them build an awareness of linguistic beauty in speaking and writing. College students can speak English but most are Chingish and prosy, poetry can elevate their expression to beautiful level. They will not only be able to speak and write, but speak and write beautifully.

3) Study of poetic features: phonetic, syntactic, typological;

In order to help students to gain "comprehensible input", teachers should simplify the language. Poetic language are pearls which can be analyzed under microscope. Now, both meaning and form should be paid attention to. Complete understanding of the form is the basis for the comprehension of the meaning. Here, sense and sound are perfect combined. Sound is the echo of sense.

4) Discussion: teacher-student and student-student interaction about the language, thought, culture, etc;

Teacher-student interaction should be on equal basis. Student-student interaction will be more interesting.

Interaction will create a democratic atmosphere in language learning. This low-anxiety atmosphere can best stimulate students output in a foreign language; in return, this output will motivate students to absorb more.

5) Imitative writing and speaking: productive output

It has long been researched how to transfer the declarative knowledge into procedural knowledge. Imitation method is a very good one to realize such transference. By imitation, students make some "comprehensible output". As Swain (1985) holds, this output will 1) make learners concentrate on the language, 2) promote learner to make hypothesis and verification towards the structure and meaning of the target language, 3) have metalanguage functions and 4) promote the automation of expression in the target language. During imitation, students can get a deeper sense of the rhyme scheme, meter arrangement, choice of diction and discourse arrangement. They will verify what they have learned in their writing and speaking and this will strengthen the acquisition of poetic devices. Ultimately, this will internalize a sense of rhyme, rhythm and meter in their writing and speaking.

6) Translation practice: This will train their translation ability and cultivate their interest in translation.

7) Comparative study: compare the poem with Chinese literary works. This may activate their literary imagination and cultural sense, contributing to a universal sense about humanity. 
The following is a diagram of the sequences in the teaching of poetry in English in college English class:

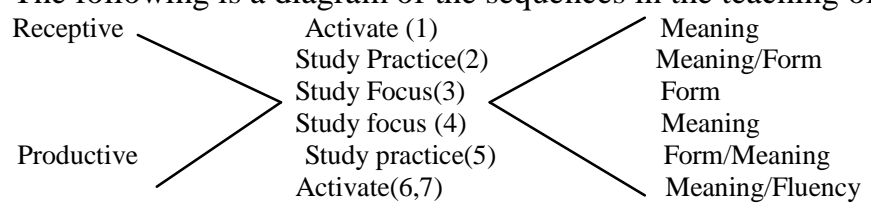

Since the diagram is similar to an hourglass in shape, we may name it Hourglass model of teaching.

\section{CONCLUSION}

The teaching of poetry in English has long been neglected in College English class in China. However, if we organize the sequences of teaching in a logically progressive way in respect of the acquisition procedure, it is possible for us to make the best use of poetry in English as an object in foreign language classes. Hourglass model of teaching absorbs the theoretical nutrition from Krashen's input hypothesis and affective hypothesis, Long's interaction hypothesis, Swain's comprehensible hypothesis, Littlewoods's gradual transfer of focus from form to meaning principle and Adair-Hauck \& Cumo-Johanssen's top-down approach and relates to the reality in China. However, the model is mainly on hypothesis and practiced by myself in my own teaching. Whether it is universally effective in the teaching of poetry in College English class still needs wider evidence to support. A positive research on a nationwide basis is expected to provide sound and firm evidence and possibly some improvements or adjustments to the sequences.

\section{REFERENCES}

[1] Breen, Michael P. and Andrew Littlejohn eds. (2002). Classroom Decision-Making. Shanghai: Shanghai Foreign Language Education Press.

[2] Brown, Doulglas, H.(2001). Teaching by Principles: An Interactive Approach to Language Pedagogy. Beijing: Foreign Language Teaching and Research Press.

[3] Davis, Paul and Eric Pearse. (2002). Success in English Teaching. Shanghai: Shanghai Foreign Language Education Press.

[4] Dubin, Fraida and Elite Olshtain. (2002). Course Design. Shanghai: Shanghai Foreign Language Education Press.

[5] Ellis, Mark and Christine Johnson. (2002). Teaching Business English. Shanghai Foreign Language Education Press.

[6] Gardner, David and Lindsay Miller. (2002). Establishing Self-Access: From Theory to Practice. Shanghai Foreign Language Education Press.

[7] Krashen,S. (1982). Principles and Practice in second language acquisition. Pergamon.

[8] Long, M. (1983). Linguistic and conversational adjustments to non-native speakers. Studies in Second Language Acquisition 5(2):177-93.

[9] Nuttal, Christine. (2002). Teaching Reading Skills in a Foreign Language. Shanghai: Shanghai Foreign Language Education Press.

[10] Parrish, Betsy. (2004). Teaching Adult ESL: A Practical Introduction. Beijing: Higher Education Press.

[11] Rivers, Wilga M. and Mary S. Temperley. (1978). A Practical Guide to the Teaching of English as a Second or Foreign Language. New York: Oxford University Press.

[12] Shrum, Judith L. and Eileen W. Glisan. (2004). Contextualized Language Instruction. Beijing: Foreign Language Teaching and Research Press.

[13] Widdowson, H.G. (1978/1986). Teaching Language as Communication. Shanghai Foreign Language Education Press.

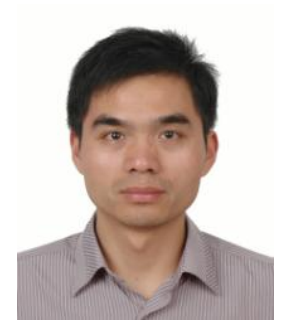

Zeyuan Hu was born in Duchang, Jiujiang City, Jiangxi Province, China in 1977. He received his B/A and M/A in English Language and Literature from Central South University, China, in 1999 and 2002. He is currently a lecturer in the college of foreign languages in Zhejiang Gongshang University, Hangzhou, Zhejiang Province, China. His research interests include English Language Teaching as a foreign language and English poetry. 